\title{
Botulinum toxin type $A$ products are not interchangeable: a review of the evidence
}

This article was published in the following Dove Press journal:

Biologics: Targets and Therapy

6 October 2014

Number of times this article has been viewed

\section{Mitchell F Brin ${ }^{1,2}$ \\ Charmaine James ${ }^{3}$ \\ John Maltman'}

'Allergan, Inc., Irvine, CA, USA; ${ }^{2}$ Department of Neurology, University of California, Irvine, CA, USA $;{ }^{3}$ Allergan, Marlow, UK

Video abstract

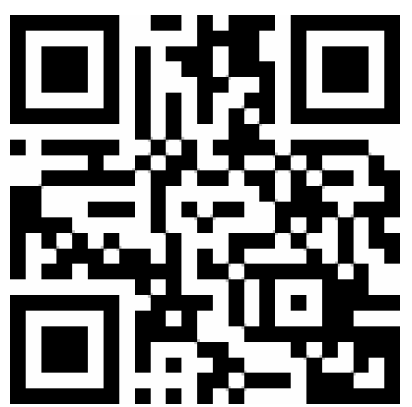

Point your SmartPhone at the code above. If you have a QR code reader the video abstract will appear. Or use: http://dvpr.es/lpWIre5
Correspondence: Mitchell F Brin Allergan, Inc., 2525 Dupont Drive, Irvine, CA USA 92612

Tel +l 7I42464429

Email brin_mitchell@allergan.com
Abstract: Botulinum toxin type A (BoNTA) products are injectable biologic medications derived from Clostridium botulinum bacteria. Several different BoNTA products are marketed in various countries, and they are not interchangeable. Differences between products include manufacturing processes, formulations, and the assay methods used to determine units of biological activity. These differences result in a specific set of interactions between each BoNTA product and the tissue injected. Consequently, the products show differences in their in vivo profiles, including preclinical dose response curves and clinical dosing, efficacy, duration, and safety/adverse events. Most, but not all, published studies document these differences, suggesting that individual BoNTA products act differently depending on experimental and clinical conditions, and these differences may not always be predictable. Differentiation through regulatory approvals provides a measure of confidence in safety and efficacy at the specified doses for each approved indication. Moreover, the products differ in the amount of study to which they have been subjected, as evidenced by the number of publications in the peer-reviewed literature and the quantity and quality of clinical studies. Given that BoNTAs are potent biological products that meet important clinical needs, it is critical to recognize that their dosing and product performance are not interchangeable and each product should be used according to manufacturer guidelines.

Keywords: onabotulinumtoxinA, abobotulinumtoxinA, incobotulinumtoxinA, glabellar lines, non-interchangeability

\section{Introduction}

Botulinum neurotoxins (BoNTs) are bacterial exotoxins that inhibit vesicular neurotransmitter release by interacting with the exocytotic release mechanism. Their ability to reduce muscular contraction led to the idea that local injection of BoNTs may be useful for overactive muscle conditions, and in the late 1970s, botulinum toxin type A (BoNTA) was tested in human patients with strabismus. ${ }^{1}$ The success of this treatment in relaxing extraocular muscles led to the development of BoNTA for focal dystonias and the eventual commercialization of several different BoNT products worldwide (Table 1). The main three BoNTA products available today are manufactured by Allergan (onabotulinumtoxinA; Allergan, Inc., Irvine, CA, USA), Ipsen (abobotulinumtoxinA; Ipsen Ltd, Slough, UK), and Merz (incobotulinumtoxinA, Merz Pharmaceuticals GmbH, Frankfurt am Main, Germany).

Due to differences in clinical performance (duration, dose, efficacy, immunogenicity, etc), BoNTA products cannot be considered interchangeable. These clinical differences result from underlying differences in basic manufacturing processes, formulation, and 
Table I Main three BoNTA products

\begin{tabular}{|c|c|c|c|}
\hline Manufacturer & $\begin{array}{l}\text { Product } \\
\text { name(s) }\end{array}$ & $\begin{array}{l}\text { Cosmetic } \\
\text { product names } \\
\text { in Europe }\end{array}$ & $\begin{array}{l}\text { Nonproprietary } \\
\text { name (United } \\
\text { States*) }\end{array}$ \\
\hline \multirow[t]{3}{*}{ Allergan } & Botox $^{\circledR}$, & Vistabel ${ }^{\circledR} /$ & Onabotulinumtoxin $A$ \\
\hline & ВОтОХ ${ }^{\circledR}$ & Vistabex $^{\circledR}$ & \\
\hline & Cosmetic & & \\
\hline Ipsen & Dysport $^{\circledR}$ & Azzalure ${ }^{\circledR}$ & Abobotulinumtoxin $\mathrm{A}$ \\
\hline Merz & Xeomin $^{\circledR}$ & Bocouture $^{\circledR}$ & IncobotulinumtoxinA \\
\hline
\end{tabular}

Notes: *Established by US Food and Drug Administration, April 2009, and accepted in Canada and several European and Latin American countries in addition to the peer-reviewed literature. Allergan, Inc. (Irvine, CA, USA). Ipsen Ltd (Slough, UK). Merz Pharmaceuticals GmbH (Frankfurt am Main, Germany).

Abbreviation: BoNTA, botulinum toxin type $A$.

potency testing methods that result in distinct unit potencies and dose response curves for each product.

The apparent existence of conflicting information in the literature regarding the differences between products that are evident in some studies but not others suggests that the products act differently depending on the clinical and experimental conditions. It is not uniformly possible to predict which parameters, systems, tissues, species, indications, etc will show differences; nevertheless, based on the scientific body of knowledge, significant conclusions can be drawn. Controversy in the literature over potential dose conversion factors reflects the underlying differences between products, which, because of their biological nature, simply do not fit into a neat, one-size-fits-all interchangeability package as may chemically synthesized drugs.

In this review, we provide evidence as to why BoNTA products are not interchangeable and shed light on reasons that most published studies show differences between products while others do not. We discuss the fundamental properties of these medications that impart their unique biological characteristics and consider how these differences influence their in vivo activity as evident in both preclinical and clinical studies. In addition, in order to obtain regulatory approval, each medication must be individually investigated to establish appropriate efficacy and safety parameters for use in a given indication. We discuss how the studies supporting these approvals provide dosing guidance, safety information, and documentation of clinical efficacy, and increase confidence in each product's clinical utility. Finally, we consider implications of non-interchangeability regarding BoNTA products and approval status.

\section{Why BoNTA products are not interchangeable Manufacturing process}

A prerequisite to understanding why BoNTA products are not interchangeable is an appreciation of their biological nature.
Unlike chemically synthesized drugs that are produced through a series of well-defined chemical reactions, biological products are produced by living organisms or cells. Biological products are principally proteins, as are BoNTAs. Proteins are typically much larger and more structurally complex than chemically synthesized drugs; for example, with a molecular weight of $150 \mathrm{kDa}$, the BoNTA core protein is hundreds or even a thousand times larger than most conventional synthetic drugs. ${ }^{2}$

Due to their size and chemical composition, proteins twist and fold in characteristic ways (ie, secondary and tertiary structures) that are critical to their biological activity, including cellular binding and activation. Therapeutic proteins are difficult to manufacture, and even seemingly small modifications can alter the protein's clinical profile. An important example of this occurred with an erythropoietin product that led to an unexpectedly high incidence of pure red-cell aplasia among patients following a change in manufacturing process. ${ }^{3}$ This side effect was traced to a leachate in new rubber stoppers used in the product's vials, which caused a cross-reactive immune response in some patients. In another example, the biological product alglucosidase alfa acquired an alteration in its carbohydrate structure when production was upscaled, which involved growing the protein in larger tanks. ${ }^{4}$ Because this type of change can alter in vivo activity, the United States Food and Drug Administration (FDA) required the manufacturer to consider alglucosidase alfa produced in the larger tanks as a separate product. ${ }^{5}$ Due to the structural and biochemical complexities, sensitivity to manufacturing methods, and difficulty in fully characterizing the activities of biological products, manufacturing this class of medications is described as the "process is the product". ${ }^{6}$

BoNTA production and formulation for clinical use was pioneered by Professor Edward Schantz, who described the procedure in several reviews. ${ }^{7,8}$ Today, the manufacturing procedures for the main commercially-available BoNTA products are tightly controlled, with each process step subject to regulatory approval. Table 2 shows the general manufacturing steps for each of the main BoNTA products, illustrating some similarities and differences.

Manufacture of all BoNTA products begins with Clostridium botulinum bacteria. In nature, these bacteria exclusively produce BoNTs as protein complexes of various sizes, with the neurotoxin serotype and protein composition of the complex dependent on the strain of the organism..$^{22,23}$ Proteolytic bacterial strains activate the single-chain 
Table 2 Comparison of manufacturing methods for BoNTA products

\begin{tabular}{|c|c|c|c|}
\hline & Allergan $^{9-12}$ & Ipsen $^{13-17}$ & Merz $^{18-21}$ \\
\hline $\begin{array}{l}\text { Fermentation (strain } \\
\text { of Clostridium botulinum) }\end{array}$ & Hall (Allergan) strain & Hall strain & Hall (ATCC 3502) strain \\
\hline Purification method & Crystallization & Chromatography & Chromatography \\
\hline Purification product & $\begin{array}{l}\text { BoNTA } \sim 900 \mathrm{kDa} \text { complex } \\
\text { protein }\end{array}$ & $\begin{array}{l}\text { BoNTA complex sizes }<500 \mathrm{kDa} \\
\text { (exact weights and composition have } \\
\text { not been reported by the manufacturer) }\end{array}$ & I50 kDa BoNTA protein only \\
\hline Unit testing & $\begin{array}{l}\text { - Diluted with saline } \\
\text { - Cell-based potency assay specific } \\
\text { to Allergan BoNTA product }\end{array}$ & $\begin{array}{l}\text { - Diluted with gelatin phosphate buffer } \\
\text { - } \mathrm{LD}_{50} \text { assay specific to Ipsen BoNTA } \\
\text { product }\end{array}$ & $\begin{array}{l}\text { Diluent information unavailable, } \\
\text { but human serum albumin added } \\
\text { - } \text { LD }_{50} \text { assay specific to Merz } \\
\text { BoNTA product }\end{array}$ \\
\hline Excipients & $\begin{array}{l}\text { In } 100 \text {-unit vial } \\
\text { - } 900 \mu g \text { sodium chloride } \\
\text { - } 500 \mu g \text { human serum albumin }\end{array}$ & $\begin{array}{l}\text { In 500-unit vial } \\
\text { - } 2.5 \mathrm{mg} \text { lactose } \\
\text { - } 125 \mu \mathrm{g} \text { human serum albumin }\end{array}$ & $\begin{array}{l}\text { In } 100 \text {-unit vial } \\
\text { - } 4.7 \mathrm{mg} \text { sucrose } \\
\text { - I mg human serum albumin }\end{array}$ \\
\hline Finishing & Vacuum dried & Freeze dried & Lyophilized \\
\hline
\end{tabular}

Notes: Allergan, Inc. (Irvine, CA, USA). Ipsen Ltd (Slough, UK). Merz Pharmaceuticals GmbH (Frankfurt am Main, Germany). Abbreviations: ATCC, American Type Culture Collection; BoNTA, botulinum toxin type A; $\mathrm{LD}_{50}$, median lethal dose.

neurotoxin protein in a process called nicking, resulting in a dichain protein linked by a disulfide bond., ${ }^{7,24}$ Following fermentation, the proteins are isolated and purified; some products are purified to retain one or more neurotoxin protein complexes as produced by the bacteria and others retain only the $\sim 150 \mathrm{kDa}$ neurotoxin itself (Table 2).

The bulk drug substance BoNTA preparations are reconstituted and diluted for biological activity testing. Although international standards for the activity of many biological products are established by the World Health Organization, ${ }^{25}$ no international standard exists for BoNTA products. As a result, each manufacturer employs its own proprietary assay methods for testing potency units that includes a productspecific reference standard. For this reason, units of biological activity are specific to each BoNTA product and unit doses are not interchangeable.

Following unit testing, excipients are added to BoNTA drug substance to provide bulk and stability to the drug product during dilution for clinical use. This step is necessary because of the extreme potency of BoNTAs and the miniscule amount of protein needed to produce a clinical response when injected for a local effect in the target tissue. ${ }^{8}$ These formulated preparations are then subjected to finishing processes that for all BoNTA products involve some method of drying. AbobotulinumtoxinA is freeze-dried and incobotulinumtoxinA is lyophilized, both processes in which the liquid is frozen and the ice evaporated under low pressure. OnabotulinumtoxinA is vacuum dried, in which the liquid is removed under reduced air pressure without the freezing step. The BoNTA products are packaged into vials and potency of the finished drug product is tested prior to release, using the proprietary reference standard. If the potency and associated release specifications are met, product is released for distribution and clinical use.

\section{Neurotoxin accessory proteins}

As noted previously, BoNTs are synthesized by $C$. botulinum as protein complexes that contain the $\sim 150 \mathrm{kDa}$ neurotoxin protein along with one or more non-toxin proteins, the neurotoxin accessory proteins (NAPs). Various strains of bacteria produce protein complexes of different sizes, but all of the type A strains produce different size complexes of $\sim 300 \mathrm{kDa}, \sim 500 \mathrm{kDa}$, and $\sim 900 \mathrm{kDa} ;{ }^{22,26}$ none of the type $\mathrm{A}$ strains produce the $\sim 150 \mathrm{kDa}$ without NAPs. OnabotulinumtoxinA and abobotulinumtoxinA contain neurotoxin protein complexes, although they are different sizes (Table 2); incobotulinumtoxinA contains the $\sim 150 \mathrm{kDa}$ neurotoxin protein only, devoid of any NAPs.

Once the BoNTA proteins are injected into tissues, they diffuse or spread based on interactions with their microenvironment, including interactions with other proteins as determined by their steric, rheologic, and biochemical characteristics. The fluid environment also influences interactions between the $\sim 150 \mathrm{kDa}$ BoNTA protein and NAPs, which dissociate over time.

The time it takes for NAPs to dissociate from the $\sim 150 \mathrm{kDa}$ BoNT protein following injection into muscle or subcutaneous tissue in vivo is not known, but likely depends on a variety of factors - some of which have been studied in vitro or following oral ingestion. ${ }^{27,28}$ Several studies have found that the $\sim 150 \mathrm{kDa}$ BoNTA protein remains largely associated with NAPs at physiological pH levels. ${ }^{28,29}$ However, others have suggested that the neurotoxin-NAP complex dissociates prior to or shortly after injection. ${ }^{20,30}$ For example, one 
study that evaluated a laboratory preparation of BoNTA (900 kDa complex) at $\mathrm{pH}$ values of 6.0 to 7.6 found that NAP-neurotoxin dissociation occurred in less than 1 minute at $\mathrm{pH}$ values greater than 7.0. ${ }^{30}$ However, these studies were performed with unformulated BoNTA proteins, which may have influenced the results, as human serum albumin (HSA; in the formulated products) is a known protein stabilizer. Eisele et al analyzed formulated onabotulinumtoxin A and abobotulinumtoxinA, concluding that the pharmaceutical products do not contain the neurotoxins in complexed form. ${ }^{30}$ However, the experimental reconstitution method necessary to achieve high neurotoxin concentrations for analysis (ie, 800 $\mathrm{U} / \mathrm{mL}$ for all products) may have influenced the integrity of the complex with resultant high excipient and salt concentrations not seen when the product is used clinically. Moreover, the anion exchange column used may have itself increased $\mathrm{pH}$ levels ${ }^{31}$ and/or set up electrostatic forces that caused NAP-neurotoxin dissociation.

A role for NAPs in the immune response to BoNTA injections has also been investigated. ${ }^{32-34}$ During clinical treatment, antibodies may develop against the NAPs, but these do not interfere with or neutralize clinical activity ("non-neutralizing"). ${ }^{33,35}$ Preclinical evidence suggests that the NAPs may physically protect the neurotoxin ${ }^{32}$ so that the immune system doesn't "see" the portion of the toxin that would engender formation of neutralizing antibodies - antibodies that may interfere with clinical response.

\section{Biological assay parameters and unit dosing}

As introduced above, the biological assay used to determine biological activity of bulk drug substance used to manufacture each individual product has a direct bearing on clinical dosing. Allergan, Ipsen, and Merz use median lethal dose $\left(\mathrm{LD}_{50}\right)$ tests to assess potency of the bulk drug substance, but the tests are conducted differently using proprietary methods. Biological assays involving animals are sensitive to variations in animal strain, age, sex, diet, temperature, caging, season, and specific experimental procedures such as the liquid used to dilute the product. ${ }^{36}$ In fact, individual products can be differentially affected by different diluents. ${ }^{21,37,38}$ Notably, manufacturers of the main BoNTA products use different diluents for $\mathrm{LD}_{50}$ testing: Allergan uses saline (the diluent also used for clinical reconstitution), ${ }^{38}$ and Ipsen uses gelatin phosphate buffer. ${ }^{14}$ Merz adds HSA as a stabilizer to its undisclosed diluent, ${ }^{21}$ and stabilizers have been shown to enhance the activity of BoNTA products at low concentrations in preclinical tests. ${ }^{39}$
The mouse-defined $\mathrm{LD}_{50}$ has been the global standard for BoNTA potency testing, used by all manufacturers. Allergan implemented a cell-based potency assay optimized for onabotulinumtoxinA, which has been approved by global regulatory agencies as a replacement for an animal $\mathrm{LD}_{50}$ test. ${ }^{11}$ This cross-validated assay does not change the product or product potency, but is an important step in reducing the use of animals for testing.

Biopharmaceutical assays typically include an international standard against which potency is referenced ("reference standard"). As noted previously, BoNT products do not have international reference standards that can be applied across products. Each manufacturer uses a unique, product-specific reference standard for biological activity testing.

The non-interchangeability of units was demonstrated in a study that examined incobotulinumtoxin $A$ and onabotulinumtoxinA in the Allergan $\mathrm{LD}_{50}$ assay. ${ }^{38}$ In this assay, the products were diluted in normal saline and compared against the Allergan 100-unit standard. Under these assay conditions, the activity of incobotulinumtoxinA was less than 100 Allergan units (ie, 69 to 78 units for three different lots). These results were confirmed in several orthogonal assays, including an enzymatic cleavage assay, the Digit Abduction Score assay, as well as replication of the $\mathrm{LD}_{50}$ results. ${ }^{40,41}$ In a separate study that compared these two products in the Merz $\mathrm{LD}_{50}$ assay, in which the products were diluted with a solution containing added HSA as a stabilizer and were compared against the Merz standard, potency was found to be comparable. ${ }^{21}$ These results confirm that the potencies of the two BoNTA products were differentially affected by the diluent and stabilizers, indicating that, due to underlying product differences, assay conditions markedly influence potency measurements.

The differences in biological assays and the resultant variations in biological activity among the BoNT products have long been recognized by regulatory agencies, when a "unit non-interchangeability" clause became part of class labeling in the United States with the approval of rimabotulinumtoxinB in 2000, the serotype B product, ${ }^{42}$ and by 1994 in Europe (Allergan prescribing information July 20, 1994), where both abobotulinumtoxinA and onabotulinumtoxinA were marketed. This clause currently states that:

The potency Units of [product name] for injection are specific to the preparation and assay method utilized. They are not interchangeable with other preparations of botulinum toxin products and, therefore, units of biological activity of 
[product name] cannot be compared to nor converted into units of any other botulinum toxin products assessed with any other specific assay method..$^{9,15,16,19,43}$

Indeed, regulatory agencies in Europe and most other countries worldwide require a statement of unit noninterchangeability among BoNT products. ${ }^{43,44}$

\section{Nomenclature}

In order to reinforce the individual potencies of BoNT products and prevent medication errors, the US FDA determined that each product would have its own nonproprietary name as listed in Table $1 .{ }^{45}$ Historically, the abbreviation BTX had been commonly used in the literature to refer to either all BoNTs or specifically to the Allergan product $\left(\mathrm{BOTOX}^{\circledR}\right)$, thereby generating confusion. This was further confounded by Lanzhou's toxin being commercialized under the name "BTXA". The FDA-stipulated nonproprietary names help to unambiguously identify each BoNT product, providing a standardized terminology to minimize the potential for medication errors and enable accurate scientific communication.

\section{Preclinical and clinical comparison of BoNTA products}

Basic differences in manufacturing, formulation, and biological activity testing can manifest as in vivo differences (efficacy, safety, immunogenicity, etc) that may become apparent in comparative preclinical models and clinical studies. However, not all studies demonstrate product differences, which in some cases may be due to methods used or, if replicable, may represent a true absence of a relevant difference.

\section{Dose-response data}

Dose-response is a central pharmacologic parameter, important in determining the therapeutic dose range associated with an acceptable efficacy and safety profile (the "benefit-risk" proposition). In preclinical studies of muscle weakening efficacy, full dose-response curves that identify 50\% maximal (median effective dose $\left[\mathrm{ED}_{50}\right]$ ) effects indicate that muscle weakening efficacy is significantly different among the three main BoNTA products, as the units of the products are not equipotent under experimental conditions. ${ }^{40,46}$

In humans, full dose-response curves are not typically generated due to the potential for adverse effects at higher doses. Some studies have examined multiple doses within circumscribed ranges. Dose-response data for
onabotulinumtoxinA in treating hyperfunctional glabellar lines showed that 20 units was not significantly different from 30 or 40 units, but that 10 units was statistically significantly less effective, identifying 20 units as the recommended dose. ${ }^{47}$ Dose-response data for abobotulinumtoxinA in glabellar lines showed that 75 units was more effective than 50 or 25 units (responder analysis), and that 50 units was more effective than 25 units, with 50 units associated with the highest patient satisfaction. ${ }^{48}$ The authors attribute this to an optimal equilibrium between efficacy and preservation of facial expression at the 50-unit dose. The incobotulinumtoxinA data suggested a dose-response with 10,20 , and 30 units in subjects with moderate or severe glabellar lines, with responder rates of $50 \%, 75 \%$, and $92 \%$, respectively. ${ }^{49}$

\section{Comparative clinical trials}

A review of the clinical trials comparing the effects of different BoNTA products in the literature reveals disparate and often confusing conclusions. Studies comparing onabotulinumtoxinA with abobotulinumtoxinA have, for years, attempted to identify a dose conversion ratio at which the products could be interchanged. ${ }^{50-55}$ The difficulty identifying a single dose ratio between products reflects the underlying differences between product efficacy dose-response across and within indications, and in disparities between efficacy and adverse events at a specified dose ratio.

More recently, incobotulinumtoxinA has been compared to onabotulinumtoxinA in blepharospasm, cervical dystonia, and glabellar lines. ${ }^{18,56-58}$ Most of these studies have compared the products at the same labeled unit doses and were non-inferiority trials, ${ }^{18,56,57}$ which are designed to show that the effect of one treatment is not inferior to that of an active comparator treatment by more than a specified statistical margin..$^{59}$ The types of conclusions that can be drawn from these studies also differ: conclusions about equivalence, or equipotency, cannot be made based on non-inferiority clinical trials, although such claims have been made; ${ }^{56,57,60}$ in contrast, conclusions about statistically equivalent efficacy on a given measure (at a specific time point) can be made based on equivalence studies, provided that the equivalence margins are prespecified.

However, one published glabellar lines study compared these two products at different doses (20 units of onabotulinumtoxinA and 30 units of incobotulinumtoxinA) using an equivalence design, ${ }^{58}$ which assesses whether the products are statistically equivalent on a given efficacy 
measure (ie, the true treatment difference is likely to lie between a lower and an upper equivalence level of clinically acceptable differences) ${ }^{61}$ This equivalence study found that 20 units of onabotulinumtoxinA was as effective as 30 units of incobotulinumtoxinA at the primary time point, despite the $50 \%$ difference in doses. ${ }^{58}$ At later time points, equivalence was not established due to a trend toward a higher percentage of responders with 20 units of onabotulinumtoxinA. This later observation illustrates that two drugs may be statistically equivalent at a specific time point(s), but may not be such at other points. Therefore, notwithstanding that equivalence was established at the prespecified time point, the clinical profiles of the two drugs are not identical.

A small study compared 30 units of onabotulinumtoxinA with 20 units of incobotulinumtoxinA for the treatment of glabellar lines. ${ }^{62}$ In this study, $100 \%$ of subjects treated with either product exhibited at least a 1-point improvement on the outcome scale and $94 \%$ of subjects treated with either product exhibited at least a 2-point improvement. The authors concluded that 30 units of onabotulinumtoxinA was "non-superior" to 20 units of incobotulinumtoxinA. Both treatments were highly effective in this study; however, with $100 \%$ and $94 \%$ of subjects improving, there was no margin within which to detect differences (ie, a ceiling effect).

Results of comparative studies depend on a variety of factors, including doses tested, study design, frequency of follow up, and potential indication under study. Sensitivity of effectiveness rating scales may also influence results; ${ }^{63,64}$ for instance, patients may perceive a difference between products even though they show the same rating on a given scale. Moreover, comparative studies do not test full doseresponse curves for efficacy and safety/adverse events but rather typically select a single dose of each product that is compared at a few follow-up time points. For example, non-inferiority trials comparing incobotulinumtoxinA to onabotulinumtoxinA reported only two time points: 4 and 12 weeks, ${ }^{57} 3$ and 16 weeks, ${ }^{18}$ and 4 and 16 weeks. ${ }^{56}$ The comparative clinical profiles cannot be fully assessed based on only one or two time points (eg, at peak effect or during the period of waning clinical effects). Assessing outcomes at peak effect is sensitive enough to differentiate BoNTAs from placebo, but may not be sensitive enough to differentiate between two medications that are both effective; similarly, one or two time points are not sensitive enough to compare different doses of the same medication.

A lack of significant difference in efficacy at single or limited time points cannot be equated to interchangeability; the products may show differences at other points along the efficacy dose-response curves, as well as differences in dose-dependent adverse events (Figure 1). Moreover, results obtained under a given set of conditions for a given indication cannot be assumed to apply to other indications where different muscles, glands, or organs may be injected; this may be attributable to product-specific tissue interactions.

\section{Onset of action}

Following intramuscular injection in humans, most data suggest that onset of action of all three main BoNTA products is within the first few days of injection and is similar across products, ${ }^{48,65-70}$ although this result is not universal. ${ }^{71,72}$

\section{Duration of effect}

Duration of effect is an important outcome because it has meaningful implications for frequency of injection and patient satisfaction. Increased treatment frequency potentially increases costs.

In placebo-controlled studies, the effects of the three main BoNTA products last approximately 3 to 4 months following injection into skeletal muscles at doses specified in the product labels for each indication., ${ }^{9,16,19}$ However, duration is difficult to compare between studies because of varied
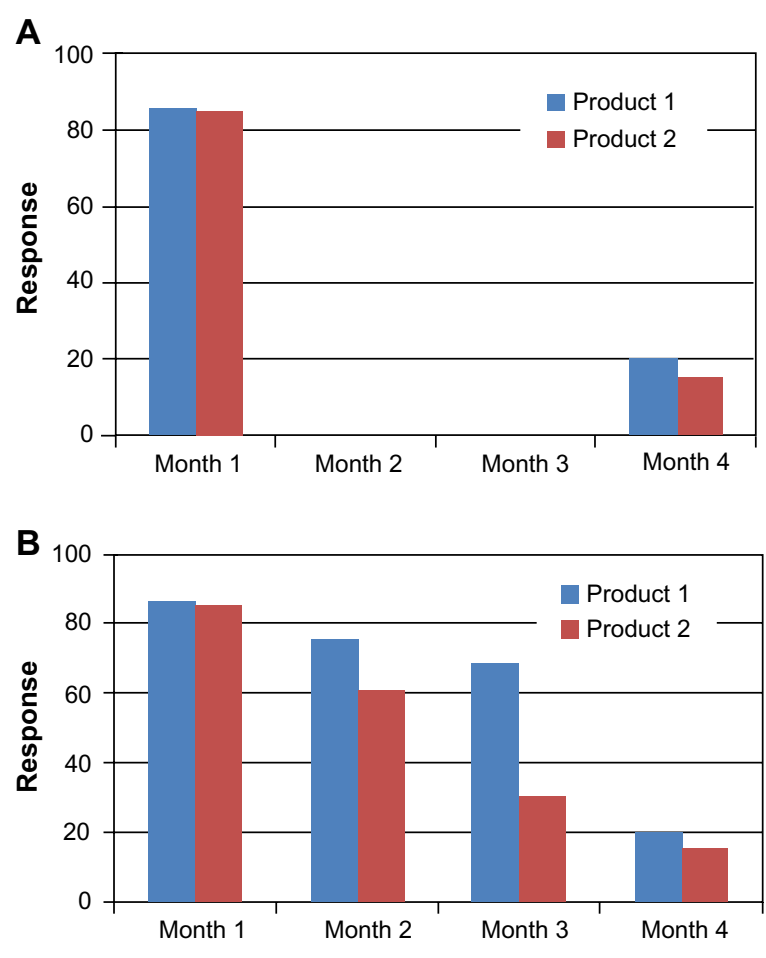

Figure I Comparison of clinical response of two hypothetical BoNTA products. Notes: (A) Graph showing hypothetical response at months I and 4 for two different products. Assessed at only month I and 4, the products may appear equivalent. (B) Graph showing hypothetical response at months I, 2, 3, and 4 for the same two products. The products clearly exhibit different pharmacodynamics, as evidenced at months 2 and 3 . 
definitions, including duration of peak clinical effect, ${ }^{73}$ time to waning of clinical effect, ${ }^{56}$ patients meeting the predefined responder definition at each time point, ${ }^{47} 80 \%$ loss of clinical benefit of varied definitions, ${ }^{74}$ complete loss of clinical response (ie, return to baseline), ${ }^{74}$ and time to retreatment. ${ }^{75}$ The latter measure is often complicated by prescheduled treatment visits, which are typically at 3-month intervals, permitting an approximate but clinically relevant assessment of duration.

Studies comparing type A products have not always drawn the same conclusions, not only due to product performance differences, but likely also due to the different methods of measuring duration in various comparative studies. The non-inferiority studies comparing onabotulinumtoxinA and incobotulinumtoxin $\mathrm{A}$ at the same labeled unit doses did not find differences in duration (assessed as time to waning of clinical effect [blepharospasm and cervical dystonia studies] $]^{18,56}$ or percentage of responders at 12 weeks [glabellar lines]). ${ }^{57}$ Another double-blind glabellar lines study did not find significant differences in duration of the three main type A products as assessed by a blinded comparison of muscle activity videos at 120, 150, and 180 days versus baseline (21 labeled units of onabotulinumtoxinA or incobotulinumtoxinA, or 63 units of abobotulinumtoxinA). ${ }^{72}$ Another direct comparison study found that $23 \%$ of subjects treated with 20 units of onabotulinumtoxinA for glabellar lines relapsed at 4 months, compared with $40 \%$ of subjects treated with 50 units of abobotulinumtoxinA. ${ }^{76}$ This study included two later time points - 12 weeks and 16 weeks - both of which showed differences between products.

Several studies indicate that duration covaries with patient satisfaction. ${ }^{77,78}$ In a meta-analysis of 621 subjects treated with 20 units of onabotulinumtoxinA for glabellar lines, 84\% were responders; among responders, the median duration of effect was 120 days at maximum contraction and 131 days at repose, and satisfaction increased with duration of effect. ${ }^{77}$ Additionally, a real-world clinical study in Argentina found that 92 of 110 women treated for glabellar lines switched back to onabotulinumtoxinA from incobotulinumtoxin A, most commonly due to insufficient duration with incobotulinumtoxinA (61 of 92), although the products were used at comparable doses. ${ }^{78} \mathrm{~A}$ retrospective study of 50 patients treated with onabotulinumtoxinA for blepharospasm and then switched to incobotulinumtoxinA found that comparable numbers of patients preferred each product ( 24 versus 26 of 50), with those preferring incobotulinumtoxinA believing it to be more effective and those preferring onabotulinumtoxinA believing it to have a longer duration (significant difference in treatment intervals of 13 weeks versus 10.2 weeks; $P=0.017) .{ }^{79}$

\section{Diffusion and spread characteristics}

The main three BoNTA products are generally well-tolerated at the approved doses, and the adverse events that do occur are often attributable to spread or diffusion away from the intended area to nearby anatomical structures. Examples include dysphagia in cervical dystonia, which is due to local spread effects to swallowing musculature, and eyelid ptosis due to effects on the nearby levator muscle when treating glabellar lines.

Terminology referring to post-injection BoNT biological movement varies in the literature. Cliff et al described local movement as migration; ${ }^{80}$ Pickett et al used diffusion and migration to refer to local effects; ${ }^{81}$ Walker $^{82}$ and Hou and Jankovic ${ }^{83}$ characterized effects in local or regional muscles as local spread; and Ramirez-Castaneda et al distinguished spread as local physical movement, diffusion to a more microscopic movement of a soluble molecule's dispersion by passive transport, and migration to distant spread. ${ }^{84}$ Regulatory authorities focus on clinical phenomena, and simply use the terms diffusion, regional diffusion, or (local) spread to refer to local effects in contiguous muscle, and distant spread to refer to effects distant from the injection sites in areas non-contiguous with the injection. ${ }^{9,16,85,86}$

Different models and techniques have been used to examine BoNTA product spread and these have recently been reviewed. ${ }^{84}$ Some studies have examined the region of toxin local activity based on protein expression or electrophysiological measures, whereas others have assessed more macroscopic effects such as weakening of adjacent muscles and the anhydrosis halo that occurs in humans following injection into muscle or dermis. These models permit pharmacodynamic assessments that may be useful in evaluating differences in product characteristics. These studies indicate that local spread of the BoNTA product following injection depends on a variety of factors such as injection technique, dose, volume, dilution, and needle size, as well as the specific characteristics of the BoNTA preparation injected. ${ }^{84}$ Several articles and reviews describing the effects of injection-related parameters on preclinical and clinical variables are available. ${ }^{84,87-89}$

Distant spread has been evaluated in a preclinical model in which safety margins were generated as ratios of the $\mathrm{LD}_{50}$ (systemic effects) following intramuscular injection to the $\mathrm{ED}_{50}$ in a muscle weakening test. ${ }^{90}$ High safety margins indicate a greater separation between the dose needed 
for muscle weakening efficacy and the dose that causes systemic toxicity after intramuscular injection; death of the mice following intramuscular injection of BoNTA preparations into the hindlimb reflects systemic distribution. ${ }^{90}$ This study showed a significant difference in the safety margins of onabotulinumtoxin A and abobotulinumtoxinA, indicating different potential to diffuse out of the injected muscle under the conditions studied. ${ }^{90}$

This model has the advantage of generating full doseresponse curves for each product, and including a dose beyond which the drug has no further effect on response (maximal dose). From these curves, the $\mathrm{ED}_{50}$ and $\mathrm{LD}_{50}$ are then estimated, per usual practice in pharmacologic dose-response studies, and each experiment is replicated at least several times. Not all preclinical diffusion studies find significant differences between all BoNTA products on every measure. ${ }^{91-93}$ Potential reasons include experimental design (eg, no dose-response curve generation), variability in single experiments, and the possibility that different BoNTA products may act differently depending on the biological system studied (eg, intraspecies and interspecies differences).

In the "anhydrosis halo" model, ${ }^{94}$ sometimes referred to as an "action halo", ${ }^{95}$ the BoNT product is frequently injected into muscle or dermis, and the area of anhydrotic activity is observed using the Minor's starch iodine test to define the areas of sweating. ${ }^{96}$ The area affected by BoNT appears as a white oval of anhydrosis (ie, the anhydrosis halo or action halo) surrounded by a black region in which the sweat interacts with the starch and iodine. Several studies have compared the anhydrosis halos produced by onabotulinumtoxinA and abobotulinumtoxinA, ${ }^{94,95,97-100}$ and one study included incobotulinumtoxinA. ${ }^{101}$

These studies generally used different doses, volumes, and dose ratios. Nevertheless, taken together, the divergent results across studies further establish that the products are not interchangeable. Product performance, as demonstrated in this anhydrosis model, is a function of dose (including concentration and volume), tissue type, and product. ${ }^{84}$ However, when the dose ratios suggested by product labeling of onabotulinumtoxinA and abobotulinumtoxinA for glabellar lines ${ }^{9,16}$ are used (2.5:1 for abobotulinumtoxinA:onabotulinumtoxinA), there is a consistent pattern of differences. Additionally, relative doses of the various products used in clinical practice ${ }^{53,102}$ generally exceed the dose ratios that exhibit comparable local spread in these models. Furthermore, although the anhydrosis halo experiments differentiate products, the direct translation of these dermal effects into functional skeletal muscle effects is not established. ${ }^{97}$

\section{Adverse events/safety}

Clinical safety profiles have been established for the main three BoNTA products in various indications (see Table 3) and are reflected in the respective labeling. Additional adverse events may emerge as the products are used in wider clinical populations in which some patients will differ from the trial population. It is problematic to compare rates of adverse events across products in the registration studies due to varying experimental conditions. Of the postmarketing head-to-head studies, some have found differences in

Table 3 Approved indications ${ }^{\mathrm{a}}$ for the main botulinum neurotoxin products available in the US and EU

\begin{tabular}{|c|c|c|c|}
\hline Indication $^{a}$ & OnabotulinumtoxinA & AbobotulinumtoxinA & IncobotulinumtoxinA \\
\hline \multicolumn{4}{|l|}{ Therapeutic } \\
\hline Strabismus & US & - & - \\
\hline Blepharopsasm & US, EU & EU & US, EU \\
\hline Hemifacial spasm & EU & EU & - \\
\hline Cervical dystonia & US, EU & US, EU & US, EU \\
\hline Primary axillary hyperhidrosis & US, EU & - & - \\
\hline Focal upper-limb spasticity & US, EU & EU & EU \\
\hline Juvenile cerebral palsy (dynamic equinus foot deformity) & EU & EU & - \\
\hline Chronic migraine & US, EU & - & - \\
\hline Neurogenic detrusor overactivity & US, EU & - & - \\
\hline Overactive bladder & US, EU & - & - \\
\hline \multicolumn{4}{|l|}{ Aesthetic } \\
\hline Glabellar lines & US, EU & US, EU & US, EU \\
\hline Crow's feet lines & US, EUc & & \\
\hline
\end{tabular}

Notes: aPrecise indication wording and associated limitations vary from country to country. Consult local labeling for details; ${ }^{\mathrm{b}} \mathrm{majority}$ of EU5 countries (France, Germany, Italy, Spain, United Kingdom); 'EU mutual recognition procedure completed October 18, 2013.

Abbreviation: EU, European Union. 
adverse events, ${ }^{52,54,57}$ whereas others have not. ${ }^{55,58}$ As noted previously, lack of dose-ranging comparisons (ie, threshold dose to maximal dose), due to experimental design complexity and/or potential concerns over patient safety at the high doses, may confound safety comparisons.

The fundamental product differences generally demonstrate that if doses are selected so that peak efficacy and/or duration are comparable, adverse event rates differ. Similarly, if the adverse events profiles are similar at a specific dose ratio, then efficacy may not be comparable. Examples of this are noted in the dystonia literature. For example, Ranoux et al compared onabotulinumtoxinA and abobotulinumtoxinA in cervical dystonia. ${ }^{52}$ OnabotulinumtoxinA (mean of 104 Allergan units) was compared to abobotulinumtoxinA at a 1:3 or 1:4 dose ratio. The authors concluded that one of the products showed a better effect on impairment and pain, but had statistically significantly higher rates of adverse events than the other product at both dose ratios. A blepharospasm study that compared onabotulinumtoxinA at a mean of dose of 45 units and abobotulinumtoxinA at a mean dose of 187 units (1:4 dose ratios) found that the products exhibited similar durations of action, but that one product was associated with significantly more adverse events overall and a greater than four-fold higher rate of ptosis. ${ }^{54}$ Moreover, a dose ratio chosen for one indication may not be generalizable to other indications given the differences in disease states, routes of administration, and muscle sizes.

\section{Immunogenicity}

As foreign proteins, all BoNT products have the potential to induce an immune response that may lead to clinical nonresponse. Only antibodies that develop against the $\sim 150 \mathrm{kDa}$ neurotoxin can "neutralize" or interfere with the biological activity of BoNTs; antibodies that develop against the NAPs do not interfere with activity. ${ }^{35}$ The occurrence of neutralizing antibodies is much lower today given the refinements in manufacturing over the past several decades. ${ }^{103,104}$ With current preparations of the main three BoNTA products, the rate of neutralizing antibody formation is low; ${ }^{105}$ reported as $0 \%$ with onabotulinumtoxinA (observed at study conclusion) in glabellar lines and $1.2 \%$ in cervical dystonia, ${ }^{9,104} 0 \%$ with abobotulinumtoxinA in glabellar lines and less than 3\% in cervical dystonia, ${ }^{16}$ and $1.1 \%$ with incobotulinumtoxinA in their overall development program..$^{20,106}$ Comparative clinical trials evaluating neutralizing antibody rates have not been conducted, but the low rates across products sug- gest that a statistically significant difference would not be apparent.

It is important to distinguish between immunogenicity and clinical nonresponse. ${ }^{105}$ Loss of clinical response may occur for reasons besides neutralizing antibody formation, including a change in the pattern of muscle activity due to disease progression or posttreatment adaptation ${ }^{107}$ and patient expectations (ie, the first injection may appear to be the most effective because of the pretreatment contrast). ${ }^{108}$ Clinical studies have shown that although patients may test positive for neutralizing antibodies in an assay, they may still be clinically responsive. ${ }^{109}$ The correlation between neutralizing antibodies and clinical response is not fully understood. Consequently, clinicians may consider a reevaluation of muscles, doses, and patient expectations before proceeding to antibody testing in their patients who appear to be nonresponsive.

\section{Current regulatory approvals of BoNTA products Main BoNTA products}

Quality assurance is essential with all medications, but perhaps especially so with BoNTs given their extremely high potency. Most, but not all, regulatory agencies mandate adherence to strict guidelines governing the manufacture and clinical development of pharmaceutical products. Manufacturing processes are regulated to ensure quality, including consistency of units, lack of contamination, and purity. For approval, manufacturers must provide evidence of efficacy and safety for each indication based on well-designed clinical trials. These lengthy and costly studies provide clinicians with important dosing and injection site guidance, as well as documentation of indicationspecific efficacy and safety. As such, the body of evidence provides confidence in the product and its clinical effects for the condition it is being used to treat. Different development pathways have led to different licensed indications for each of the main BoNTA products (Table 3).

Publications of the three main BoNTA products' basic pharmacologic properties, clinical efficacy, and safety, coupled with manufacturing quality standards, lend confidence to these therapeutics. Mohindru et al presented data at the 2013 Second International Congress on Treatment of Dystonia in Hannover, Germany, documenting that, as a class, BoNTA products have been extensively researched (onabotulinumtoxinA cited in 2,838 clinical and nonclinical articles, abobotulinumtoxinA cited in 987 clinical and nonclinical articles, and incobotulinumtoxinA, cited in 87 clinical and nonclinical articles). ${ }^{110}$ Regulatory approvals and published 
peer-reviewed studies, including studies on mechanism of action, further differentiate BoNTA products beyond the differences conferred during the manufacturing and formulation processes (Figure 2).

Moreover, some studies have examined effects in non-skeletal muscle indications that involve smooth muscle and neuroglandular activity. These studies have found that the duration of action of BoNTA is much longer when injected intradermally for primary axillary hyperhidrosis ${ }^{111}$ and into the smooth muscle of the urinary bladder ${ }^{112}$ than when injected into skeletal muscle. These studies further confirm that a product's profile may vary with target tissue type.

Additionally, onabotulinumtoxinA has been explored in conditions with prominent sensory components (ie, chronic migraine, neurogenic detrusor overactivity, and idiopathic overactive bladder), and these studies have intensified research into mechanisms of action beyond the effect of BoNTA on acetylcholine release from motor neurons. Preclinical studies with onabotulinumtoxinA, ${ }^{113-116}$ as well as clinical studies on sensory-based symptoms such as migraine pain ${ }^{117,118}$ and urgency in urology, ${ }^{119}$ have indicated that effects on sensory afferents contribute to the clinical efficacy of onabotulinumtoxinA in these conditions. Given the non-interchangeability of BoNTA products, it is important to establish product-specific safety and efficacy for each condition rather than assuming that the licensed indication of one product applies to all products, as each will have its own benefit-risk profile.

\section{Other BoNTA products}

The success of BoNTA treatment for a variety of different conditions has led to the introduction of several products that have limited distribution and regulation. Various BoNTA products are now regionally approved in selected countries in Asia and South America, including Neuronox ${ }^{\circledR} /$ Meditoxin $^{\circledR}$ (Medytox, Inc., Seoul, Korea), BTXA ${ }^{\mathrm{TM}} /$ Prosigne (Lanzhou Institute of Biological Products, Lanzhou, People's Republic of China), and Botulax ${ }^{\circledR} /$ Reginox/Zentox (Hugel Inc., Chuncheon, Korea), some of which have limited peer-reviewed scientific and clinical evidence. Nevertheless, non-interchangeability applies to these products.

\section{Implications of non- interchangeability}

The implications of non-interchangeability are important because they have direct implications for clinical efficacy and safety, and the entire experience of patient satisfaction. These two intertwined dimensions are not independent, as each product establishes a specific benefit-risk profile. These factors are also influenced by product quality.

The benefit-risk proposition from one product cannot be applied to another product. For example, if a product with less biological activity were administered at unit doses based on a more potent product, patients would not experience adequate reduction in symptoms. Products used at suboptimal doses may therefore not meet patient expectations, which could lead to dissatisfaction. Moreover, patients may need more frequent office visits for reinjection, which may be inconvenient and may escalate costs. Treatment frequency is one contributing dimension for antibody formation for proteins in general, with more frequent injections increasing the potential for neutralizing antibody formation. Equally important, if a product with more biological activity were administered at unit doses based on a less potent product, patients may experience an unacceptable safety profile.

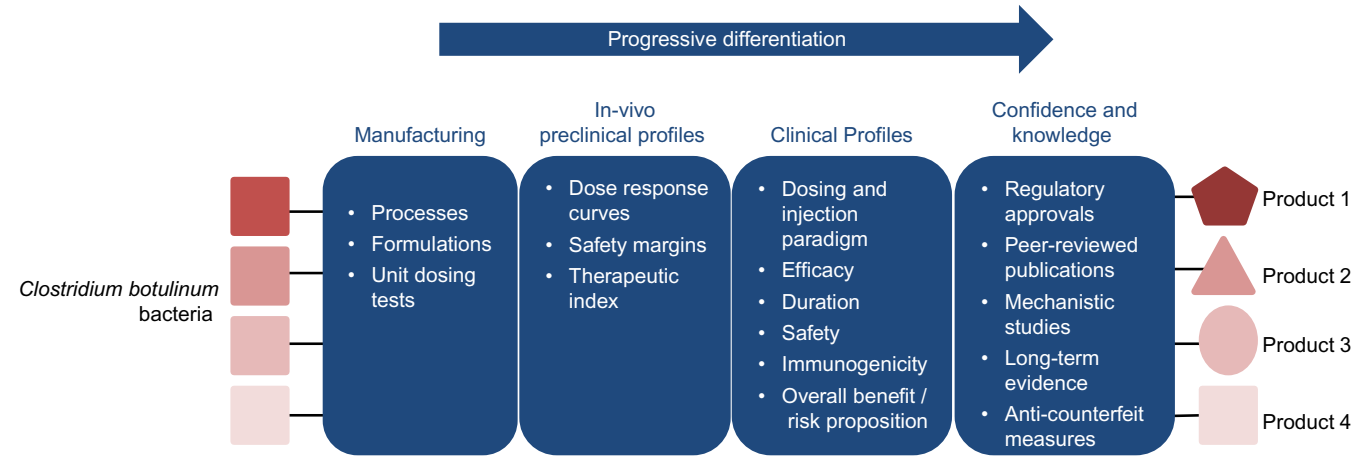

Figure 2 Progressive differentiation of four hypothetical BoNTAs.

Notes: BoNTA products are biologics derived from Clostridium botulinum bacteria. For each product (denoted as example Products I-4; not meant to correspond exactly to currently approved products), the manufacturing process, formulation, and method of determining units differ. These factors result in differences in product in vivo profiles, including preclinical dose-response curves and clinical dosing, efficacy, duration, safety/adverse events, and immunogenicity. The products are subject to further differentiation based on confidence in and knowledge of the product gained through regulatory approvals, the number and quality of clinical studies that are conducted and published in peer-reviewed journals, research into the mechanism(s) of action, long-term evidence, and anti-counterfeit measures.

Abbreviation: BoNTA, botulinum toxin type A. 
As noted above, the implementation of unique nonproprietary names by the FDA reinforces individual potencies and may prevent medication errors with potential serious side effects. ${ }^{120}$ Medication errors could lead to overdosing with consequent, potentially serious side effects.

Concerns over manufacturing processes have practical implications. To ensure quality, manufacturers of the main three BoNTA products adhere to Good Manufacturing Procedures guidelines, which require periodic inspections to ensure compliance. Each step in the manufacture of these products is subject to regulatory approval, from its synthesis by $C$. botulinum bacteria to the packaging and shipping. Variations in manufacturing process can impact purity, stability, and potency of the product, which in turn may impact predictability of clinical response and safety. This caution is particularly warranted in view of the availability of numerous BoNTA products worldwide, some of which are not subject to the full measure of regulatory scrutiny described above.

Counterfeit and unlicensed products have been periodically available for purchase over the Internet. ${ }^{121}$ In 2007, a BoNTA product available in the People's Republic of China (CNBTX-A; Nanfeng Medical Science and Technology Development Company, Shijiazhuang, People's Republic of China) was unlicensed and not accompanied by a package insert or dosing recommendations, although vials were labeled as containing 55 units. ${ }^{122}$ When this product was tested in the Allergan biological activity assay, each vial contained an equivalent of 243 Allergan units. ${ }^{122}$ If this product had been mistakenly used at the same doses as an approved product such as onabotulinumtoxinA on the assumption of unit interchangeability, serious adverse effects may have ensued.

An extreme example occurred several years ago when a highly-concentrated laboratory preparation of BoNTA was illegally administered to humans at a cosmetic clinic in Florida. ${ }^{123}$ Following exposure to this unapproved laboratory preparation, patients developed muscle weakness attributable to systemic distribution of the BoNTA preparation and were hospitalized for up to 14 weeks.

\section{Conclusion}

The non-interchangeability of BoNTA products has important implications for the benefit-risk proposition, including efficacy, safety, low immunogenicity, and long duration of action. Clinicians and patients depend on predictable therapeutics at safe and effective doses, and switching from an established efficacious dose of one BoNTA product to another product at the same or different number of labeled units cannot be expected to provide the same outcome.
For these reasons, physicians should follow manufacturer guidance when treating patients.

Furthermore, in the current health care climate, costeffectiveness is an important consideration as are confidence and predictability in the results from injection to injection, as demonstrated from robust, particularly regulatory, clinical studies.

During the past decade, clinicians have experienced expanding indications for several of the BoNTA products, primarily into skeletal muscle disorders, but also for other indications in different disease targets, such as onabotulinumtoxinA for chronic migraine and both neurogenic and idiopathic overactive bladder. Some indications have very specific dosing, which translates into an acceptable benefit-risk proposition; dosing considerations applicable to skeletal muscle do not necessarily generalize to other targets. Investment of time and effort into development of novel indications helps to increase awareness of the conditions and stimulate research into their characterization and treatment. The concepts of non-interchangeability become increasingly important as the therapeutic use of BoNTs diversifies into new disease areas.

\section{Acknowledgments}

Writing and editorial assistance was provided to the authors by MaryAnn Chapman, $\mathrm{PhD}$ and funded by Allergan Inc., Irvine, CA. The authors also acknowledge the contributions of Conor Gallagher, PhD to critical review of the manuscript.

\section{Disclosure}

The authors of this manuscript are employees of Allergan, Inc., the manufacturers of onabotulinumtoxinA. The authors report no other conflicts of interest in this work.

\section{References}

1. Scott AB. Botulinum toxin injection into extraocular muscles as an alternative to strabismus surgery. Ophthalmology. 1980;87(10): 1044-1049.

2. Schellekens H. Follow-on biologics: challenges of the "next generation". Nephrol Dial Transplant. 2005;20(Suppl 4):iv31-iv36.

3. Woodcock J, Griffin J, Behrman R, et al. The FDA's assessment of follow-on protein products: a historical perspective. Nat Rev Drug Discov. 2007;6(6):437-442.

4. Ledford H. Biotechs go generic: the same but different. Nature. 2007;449(7160):274-276.

5. Genzyme Corporation. Genzyme provides details of October Myozyme (alglucosidase alfa) Advisory Panel meeting and additional regulatory updates [press release]. Cambridge, MA: Genzyme Corporation; September 23, 2008. Available from: http://news. genzyme.com/press-release/genzyme-provides-details-octobermyozyme-alglucosidase-alfa-advisory-panel-meeting-and. Accessed September 17, 2013. 
6. Schellekens H. When biotech proteins go off-patent. Trends Biotechnol. 2004;22(8):406-410.

7. Schantz EJ, Johnson EA. Properties and use of botulinum toxin and other microbial neurotoxins in medicine. Microbiol Rev. 1992;56(1): $80-99$.

8. Schantz EJ, Johnson EA. Botulinum toxin: the story of its development for the treatment of human disease. Perspect Biol Med. 1997;40(3): $317-327$.

9. BOTOX $^{\circledR}$ (onabotulinumtoxinA) [prescribing information]. Irvine, CA: Allergan, Inc.; 2013.

10. Zhang L, Lin WJ, Li S, Aoki KR. Complete DNA sequences of the botulinum neurotoxin complex of Clostridium botulinum type A-Hall (Allergan) strain. Gene. 2003;315:21-32.

11. Fernández-Salas E, Wang J, Molina Y, Nelson JB, Jacky BP, Aoki KR. Botulinum neurotoxin serotype A specific cell-based potency assay to replace the mouse bioassay. PLoS One. 2012;7(11):e49516.

12. Lietzow MA, Gielow ET, Le D, Zhang J, Verhagen MF. Subunit stoichiometry of the Clostridium botulinum type A neurotoxin complex determined using denaturing capillary electrophoresis. Protein J. 2008;27(7-8):420-425.

13. Hambleton P. Clostridium botulinum toxins: a general review of involvement in disease, structure, mode of action and preparation for clinical use. J Neurol. 1992;239(1):16-20.

14. Panjwani N, O'Keeffe R, Pickett A. Biochemical, functional and potency characteristics of type A botulinum toxin in clinical use. Botulinum J. 2008;1(1):153-166.

15. Ipsen, Ltd. Dysport Summary of Product Characteristics [webpage on the Internet]. Surrey, UK: Datapharm Communications Ltd; 2013. Available from: http://www.medicines.org.uk/emc/medicine/870. Accessed July 13, 2013.

16. Dysport ${ }^{\circledR}$ (abobotulinumtoxin $\mathrm{A}$ ) [prescribing information]. Boulogne-Billancourt: Ipsen Biopharm Ltd; 2012.

17. Center for Drug Evaluation and Research. Center for Drug Evaluation and Research (CDER). Application \#125274. Chemistry reviews. BLA STN 125286/0. Reloxin (Botulinum Toxin Type A). Silver Spring, MD: Center for Drug Evaluation and Research; 2009. Available from: http:// www.accessdata.fda.gov/drugsatfda_docs/nda/2009/125274s000_ ChemR.pdf. Accessed October 21, 2013.

18. Roggenkämper P, Jost WH, Bihari K, Comes G, Grafe S; NT 201 Blepharospasm Study Team. Efficacy and safety of a new Botulinum Toxin Type A free of complexing proteins in the treatment of blepharospasm. J Neural Transm. 2006;113(3):303-312.

19. Xeomin (incobotulinumtoxinA) [prescribing information]. Frankfurt am Main: Merz Pharmaceuticals, LLC; 2013.

20. Frevert J, Dressler D. Complexing proteins in botulinum toxin type A drugs: a help or a hindrance? Biologics. 2010;4:325-332.

21. Dressler D, Mander G, Fink K. Measuring the potency labelling of onabotulinumtoxinA (Botox $\left({ }^{\circledR}\right)$ ) and incobotulinumtoxinA (Xeomin $\left.\left({ }^{\circledR}\right)\right)$ in an LD50 assay. $J$ Neural Transm. 2012;119(1):13-15.

22. Sakaguchi G, Kozaki S, Ohishi I. Structure and function of botulinum toxins. In: AIouf JE, editor. Bacterial Protein Toxins. London: Academic Press; 1984:435-443.

23. Hatheway C. Bacterial sources of clostridial neurotoxins. In: Simpson LL, editor. Botulinum Neurotoxin and Tetanus Toxin. San Diego, CA: Academic Press; 1989:4-24.

24. Das Gupta BR, Sugiyama H. Role of a protease in natural activation of Clostridium botulinum neurotoxin. Infect Immun. 1972;6(4):587-590.

25. WHO international biological reference preparations [webpage on the Internet]. Geneva: World Health Organization. Available from: http:// www.who.int/biologicals/reference_preparations/en/.Accessed October 24, 2013.

26. Inoue K, Fujinaga $\mathrm{Y}$, Watanabe $\mathrm{T}$, et al. Molecular composition of Clostridium botulinum type A progenitor toxins. Infect Immun. 1996;64(5):1589-1594.

27. Ohishi I, Sugii S, Sakaguchi G. Oral toxicities of Clostridium botulinum toxins in response to molecular size. Infect Immun. 1977;16(1): 107-109.
28. Wagman J, Bateman JB. Botulinum type A toxin: properties of a toxic dissociation product. Arch Biochem Biophys. 1953;45(2): 375-383.

29. Cai S, Sarkar HK, Singh BR. Enhancement of the endopeptidase activity of botulinum neurotoxin by its associated proteins and dithiothreitol. Biochemistry. 1999;38(21):6903-6910.

30. Eisele KH, Fink K, Vey M, Taylor HV. Studies on the dissociation of botulinum neurotoxin type A complexes. Toxicon. 2011;57(4): $555-565$.

31. Scopes RK. Protein Purification: Principles and Practice. 3rd ed. New York: Springer; 1994.

32. Chen F, Kuziemko GM, Amersdorfer P, Wong C, Marks JD, Stevens RC. Antibody mapping to domains of botulinum neurotoxin serotype A in the complexed and uncomplexed forms. Infect Immun. 1997;65(5):1626-1630.

33. Göschel H, Wohlfarth K, Frevert J, Dengler R, Bigalke H. Botulinum A toxin therapy: neutralizing and nonneutralizing antibodies - therapeutic consequences. Exp Neurol. 1997;147(1):96-102.

34. Kukreja R, Chang TW, Cai S, et al. Immunological characterization of the subunits of type A botulinum neurotoxin and different components of its associated proteins. Toxicon. 2009;53(6):616-624.

35. Joshi SG, Elias M, Singh A, et al. Modulation of botulinum toxin-induced changes in neuromuscular function with antibodies directed against recombinant polypeptides or fragments. Neuroscience. 2011;179:208-222.

36. Zbinden G, Flury-Roversi M. Significance of the LD50-test for the toxicological evaluation of chemical substances. Arch Toxicol. 1981;47(2):77-99.

37. McLellan K, Das RE, EkongTA, Sesardic D. Therapeutic botulinum type A toxin: factors affecting potency. Toxicon. 1996;34(9):975-985.

38. Hunt T, Clarke K. Potency evaluation of a formulated drug product containing 150-kd botulinum neurotoxin type A. Clin Neuropharmacol. 2009;32(1):28-31.

39. Sesardic D, Leung T, Gaines Das R. Role for standards in assays of botulinum toxins: international collaborative study of three preparations of botulinum type A toxin. Biologicals. 2003;31(4):265-276.

40. Brown M, Nicholson G, Ardila MC, et al. Comparative evaluation of the potency and antigenicity of two distinct BoNT/A-derived formulations. J Neural Transm. 2013;120(2):291-298.

41. Hunt T, Clarke K, Rupp D, Shimizu G, Weidler J. 50-U incobotulinumtoxinA drug product demonstrates lower potency when compared to 50-U onabotulinumtoxinA drug product with concurrent lower light-chain activity and atypical substrate cleavage. Poster presented at: 6th European Master's in Aesthetic and Anti-Aging Medicine; October 15-17, 2010; Paris, France.

42. BOTOX ${ }^{\circledR}$ [prescribing information]. Irvine, CA: Allergan, Inc.; 2001.

43. Allergan, Ltd. BOTOX 100 U. Summary of product characteristics [webpage on the Internet]. Surrey, UK: Datapharm Communications Ltd; 2013 [updated December 12, 2012]. Available from: http://www. medicines.org.uk/emc/medicine/112. Accessed July 22, 2013.

44. BOTOX ${ }^{\circledR}$ (onabotulinumtoxinA) [prescribing information]. Buenos Aires, Argentina: Allergan, Inc.; 2011.

45. Information for Healthcare Professionals: OnabotulinumtoxinA (marketed as Botox/Botox Cosmetic), AbobotulinumtoxinA (marketed as Dysport) and RimabotulinumtoxinB (marketed as Myobloc) [webpage on the Internet]. Silver Spring, MD: US Food and Drug Administration; 2013. Available from: http://www.fda.gov/Drugs/ DrugSafety/PostmarketDrugSafetyInformationforPatientsandProvide rs/DrugSafetyInformationforHeathcareProfessionals/ucm174949.htm. Accessed May 20, 2014.

46. Aoki KR, Ranoux D, Wissel J. Using translational medicine to understand clinical differences between botulinum toxin formulations. Eur J Neurol. 2006;13 Suppl 4:10-19.

47. Carruthers A, Carruthers J, Said S. Dose-ranging study of botulinum toxin type A in the treatment of glabellar rhytids in females. Dermatol Surg. 2005;31(4):414-422; discussion 422. 
48. Ascher B, Zakine B, Kestemont P, Baspeyras M, Bougara A, Santini J. A multicenter, randomized, double-blind, placebo-controlled study of efficacy and safety of 3 doses of botulinum toxin A in the treatment of glabellar lines. J Am Acad Dermatol. 2004;51(2):223-233.

49. Fulford-Smith A, Gallagher CJ, Brin MF. Multicentre, randomized, phase III study of a single dose of incobotulinumtoxinA, free from complexing proteins, in the treatment of glabellar frown lines. Derm Surg. 2013;39(7):1118-1119.

50. Sampaio C, Costa J, Ferreira JJ. Clinical comparability of marketed formulations of botulinum toxin. Mov Disord. 2004;19 Suppl 8: S129-S136.

51. Sampaio C, Ferreira JJ, Simões F, et al. DYSBOT: a single-blind, randomized parallel study to determine whether any differences can be detected in the efficacy and tolerability of two formulations of botulinum toxin type A - Dysport and Botox - assuming a ratio of 4:1. Mov Disord. 1997;12(6):1013-1018.

52. Ranoux D, Gury C, Fondarai J, Mas JL, Zuber M. Respective potencies of Botox and Dysport: a double blind, randomised, crossover study in cervical dystonia. J Neurol Neurosurg Psychiatry. 2002;72(4): 459-462.

53. Marchetti A, Magar R, Findley L, et al. Retrospective evaluation of the dose of Dysport and BOTOX in the management of cervical dystonia and blepharospasm: the REAL DOSE study. Mov Disord. 2005;20(8):937-944.

54. Nüssgens Z, Roggenkämper P. Comparison of two botulinum-toxin preparations in the treatment of essential blepharospasm. Graefes Arch Clin Exp Ophthalmol. 1997;235(4):197-199.

55. Odergren T, Hjaltason H, Kaakkola S, et al. A double blind, randomised, parallel group study to investigate the dose equivalence of Dysport and Botox in the treatment of cervical dystonia. J Neurol Neurosurg Psychiatry. 1998;64(1):6-12.

56. Benecke R, Jost WH, Kanovsky P, Ruzicka E, Comes G, Grafe S. A new botulinum toxin type A free of complexing proteins for treatment of cervical dystonia. Neurology. 2005;64(11):1949-1951.

57. Sattler G, Callander MJ, Grablowitz D, et al. Noninferiority of incobotulinumtoxinA, free from complexing proteins, compared with another botulinum toxin type A in the treatment of glabellar frown lines. Dermatol Surg. 2010;36 Suppl 4:2146-2154.

58. Moers-Carpi M, Dirschka T, Feller-Heppt G, et al. A randomised, double-blind comparison of 20 units of onabotulinumtoxinA with 30 units of incobotulinumtoxinA for glabellar lines. J Cosmet Laser Ther. 2012;14(6):296-303.

59. Snapinn SM. Noninferiority trials. Curr Control Trials Cardiovasc Med. 2000;1(1):19-21.

60. Frevert J. Content of botulinum neurotoxin in Botox $^{\circledR} /$ Vistabel $^{\circledR}$, Dysport ${ }^{\circledR} /$ Azzalure $^{\circledR}$, and Xeomin ${ }^{\circledR} /$ Bocouture $^{\circledR}$. Drugs R D. 2010;10(2):67-73.

61. Lee NJ, McDonagh M, Chan B, Peterson K, Thakurta S. Drug class review. Topical calcineurin inhibitors. Final Report. Portland, OR Oregon Health and Science University; 2008. Available from: http:// www.ncbi.nlm.nih.gov/books/NBK10462/pdf/TOC.pdf. Accessed June 5, 2014.

62. Prager W, Rappl T. Phase IV study comparing incobotulinumtoxinA and onabotulinumtoxinA using a 1:1.5 dose-conversion ratio for the treatment of glabellar frown lines. J Cosmet Dermatol. 2012;11(4): 267-271.

63. Wabbels B, Jost WH, Roggenkamper P. Difficulties with differentiating botulinum toxin treatment effects in essential blepharospasm. J Neural Transm. 2011;118(6):925-943.

64. Hobart JC, Cano SJ, Zajicek JP, Thompson AJ. Rating scales as outcome measures for clinical trials in neurology: problems, solutions, and recommendations. Lancet Neurol. 2007;6(12):1094-1105.

65. Carruthers A, Carruthers J, Lowe NJ, et al; BOTOX ${ }^{\circledR}$ Glabellar Lines I and II, Groups S. One-year, randomised, multicenter, twoperiod study of the safety and efficacy of repeated treatments with botulinum toxin type A in patients with glabellar lines. J Clin Res. 2004;7:1-20.
66. Jost WH, Blümel J, Grafe S. Botulinum neurotoxin type A free of complexing proteins (XEOMIN) in focal dystonia. Drugs. 2007;67(5): 669-683.

67. Lorenc ZP, Kenkel JM, Fagien S, et al. A review of AbobotulinumtoxinA (Dysport). Aesthet Surg J. 2013;33(Suppl 1):13S-17S.

68. Beer KR, Boyd C, Patel RK, Bowen B, James SP, Brin MF. Rapid onset of response and patient-reported outcomes after onabotulinumtoxinA treatment of moderate-to-severe glabellar lines. J Drugs Dermatol. 2011;10(1):39-44

69. Karsai S, Adrian R, Hammes S, Thimm J, Raulin C. A randomized double-blind study of the effect of Botox and Dysport/Reloxin on forehead wrinkles and electromyographic activity. Arch Dermatol. 2007;143(11):1447-1449.

70. Blitzer A, Brin MF. Use of botulinum toxin for diagnosis and management of cricopharyngeal achalasia. Otolaryngol Head Neck Surg. 1997;116(3):328-330.

71. Nestor MS, Ablon GR. Comparing the clinical attributes of abobotulinumtoxinA and onabotulinumtoxinA utilizing a novel contralateral Frontalis model and the Frontalis Activity Measurement Standard. J Drugs Dermatol. 2011;10(10):1148-1157.

72. Rappl T, Parvizi D, Friedl H, et al. Onset and duration of effect of incobotulinumtoxin $\mathrm{A}$, onabotulinumtoxin $\mathrm{A}$, and abobotulinumtoxin $\mathrm{A}$ in the treatment of glabellar frown lines: a randomized, double-blind study. Clin Cosmet Investig Dermatol. 2013;6:211-219.

73. Jankovic J, Schwartz K. Botulinum toxin injections for cervical dystonia. Neurology. 1990;40(2):277-280.

74. Brashear A, Lew MF, Dykstra DD, et al. Safety and efficacy of NeuroBloc (botulinum toxin type B) in type A-responsive cervical dystonia. Neurology. 1999;53(7):1439-1446.

75. Brashear A, Watts MW, Marchetti A, Magar R, Lau H, Wang L. Duration of effect of botulinum toxin type A in adult patients with cervical dystonia: a retrospective chart review. Clin Ther. 2000;22(12): $1516-1524$.

76. Lowe P, Patnaik R, Lowe N. Comparison of two formulations of botulinum toxin type A for the treatment of glabellar lines: a double-blind, randomized study. J Am Acad Dermatol. 2006;55(6): 975-980.

77. Glogau R, Kane M, Beddingfield F, et al. OnabotulinumtoxinA: a meta-analysis of duration of effect in the treatment of glabellar lines. Dermatol Surg. 2012;38(11):1794-1803.

78. Banegas RA, Farache F, Rancati A, et al. The South American Glabellar Experience Study (SAGE): A Multicenter Retrospective Analysis of Real-World Treatment Patterns Following the Introduction of IncobotulinumtoxinA in Argentina. Aesthet Surg J. 2013;33(7):1039-1045.

79. Chundury RV, Couch SM, Holds JB. Comparison of preferences between onabotulinumtoxinA (Botox) and incobotulinumtoxinA (Xeomin) in the treatment of benign essential blepharospasm. Ophthal Plast Reconstr Surg. 2013;29(3):205-207.

80. Cliff SH, Judodihardjo H, Eltringham E. Different formulations of botulinum toxin type A have different migration characteristics: a doubleblind, randomized study. J Cosmet Dermatol. 2008;7(1):50-54.

81. Pickett A, Dodd S, Rzany B. Confusion about diffusion and the art of misinterpreting data when comparing different botulinum toxins used in aesthetic applications. J Cosmet Laser Ther. 2008;10(3):181-183.

82. Walker FO. Botulinum toxin therapy for cervical dystonia. Phys Med Rehabil Clin N Am. 2003;14(4):749-766, vi.

83. Hou J, Jankovic J. Botulinum toxin treatment in tremors. In: Brin MF, Hallett M, Jankovic J, editors. Scientific and Therapeutic Aspects of Botulinum Toxin. Philadelphia: Lippincott Williams \& Wilkins; 2002:323-335.

84. Ramirez-Castaneda J, Jankovic J, Comella C, Dashtipour K, FernandezHH, Mari Z. Diffusion, spread, and migration of botulinum toxin. Mov Disord. 2013;28(13):1775-1783.

85. Coté TR, Mohan AK, Polder JA, Walton MK, Braun MM. Botulinum toxin type A injections: adverse events reported to the US Food and Drug Administration in therapeutic and cosmetic cases. $J \mathrm{Am}$ Acad Dermatol. 2005;53(3):407-415. 
86. Food and Drug Administration. Letter Re: Docket No FDA-2008-P0061. April 30, 2009. Silver Spring, MD: US Food and Drug Administration; 2009. Available at: http://www.fda.gov/downloads/ Drugs/DrugSafety/PostmarketDrugSafetyInformationforPatients andProviders/DrugSafetyInformationforHeathcareProfessionals/ UCM143989.pdf. Accessed October 23, 2013.

87. Karsenty G, Baverstock R, Carlson K, et al. Technical aspects of botulinum toxin type $\mathrm{A}$ injection in the bladder to treat urinary incontinence: reviewing the procedure. Int J Clin Pract. 2014;68(6):731-742.

88. Ploumis A, Varvarousis D, Konitsiotis S, Beris A. Effectiveness of botulinum toxin injection with and without needle electromyographic guidance for the treatment of spasticity in hemiplegic patients: a randomized controlled trial. Disabil Rehabil. 2014;36(4):313-318.

89. Carruthers A, Carruthers J, Cohen J. Dilution volume of botulinum toxin type A for the treatment of glabellar rhytides: does it matter? Dermatol Surg. 2007;33(1 Spec No):S97-S104.

90. Aoki KR. A comparison of the safety margins of botulinum neurotoxin serotypes A, B, and F in mice. Toxicon. 2001;39(12):1815-1820.

91. Dodd SL, Rowell BA, Vrabas IS, Arrowsmith RJ, Weatherill PJ. A comparison of the spread of three formulations of botulinum neurotoxin A as determined by effects on muscle function. Eur $J$ Neurol. 1998;5(2):181-186.

92. Rosales RL, Bigalke H, Dressler D. Pharmacology of botulinum toxin: differences between type A preparations. Eur J Neurol. 2006; 13 Suppl 1:2-10.

93. Chung ME, Song DH, Park JH. Comparative study of biological activity of four botulinum toxin type A preparations in mice. Dermatol Surg. 2013;39(1 Pt 2):155-164.

94. Trindade de Almeida AR, Marques E, de Almeida J, Cunha T, Boraso R. Pilot study comparing the diffusion of two formulations of botulinum toxin type A in patients with forehead hyperhidrosis. Dermatol Surg. 2007;33(1 Spec No):S37-S43.

95. Hexsel D, Dal'Forno T, Hexsel C, Do Prado DZ, Lima MM. A randomized pilot study comparing the action halos of two commercial preparations of botulinum toxin type A. Dermatol Surg. 2008;34(1):52-59.

96. Naumann M, Lowe NJ. Botulinum toxin type A in treatment of bilateral primary axillary hyperhidrosis: randomised, parallel group, double blind, placebo controlled trial. BMJ. 2001;323(7313):596-599.

97. Hexsel D, Hexsel C, Siega C, Schilling-Souza J, Rotta FT, Rodrigues TC. Fields of effects of 2 commercial preparations of botulinum toxin type A at equal labeled unit doses: a double-blind randomized trial. JAMA Dermatol. 2013;149(12):1386-1391.

98. Kranz G, Haubenberger D, Voller B, et al. Respective potencies of Botox and Dysport in a human skin model: a randomized, double-blind study. Mov Disord. 2009;24(2):231-236.

99. Rystedt A, Swartling C, Farnstrand C, Naver H. Equipotent concentrations of Botox and Dysport in the treatment of palmar hyperhidrosis. Acta Derm Venereol. 2008;88(5):458-461.

100. Rystedt A, Karlqvist M, Bertilsson M, Naver H, Swartling C. Effect of botulinum toxin concentration on reduction in sweating: a randomized, double-blind study. Acta Derm Venereol. 2013;93(6):674-678.

101. Kerscher M, Roll S, Becker A, Wigger-Alberti W. Comparison of the spread of three botulinum toxin type A preparations. Arch Dermatol Res. 2012;304(2):155-161.

102. Bentivoglio AR, Ialongo T, Bove F, De Nigris F, Fasano A. Retrospective evaluation of the dose equivalence of Botox $\left({ }^{\circledR}\right)$ and Dysport $\left({ }^{\circledR}\right)$ in the management of blepharospasm and hemifacial spasm: a novel paradigm for a never ending story. Neurol Sci. 2012;33(2):261-267.

103. Jankovic J, Vuong KD, Ahsan J. Comparison of efficacy and immunogenicity of original versus current botulinum toxin in cervical dystonia. Neurology. 2003;60(7):1186-1188.

104. Brin MF, Comella CL, Jankovic J, Lai F, Naumann M; CD-017 BoNTA Study Group. Long-term treatment with botulinum toxin type A in cervical dystonia has low immunogenicity by mouse protection assay. Mov Disord. 2008;23(10):1353-1360.

105. Naumann M, Boo LM, Ackerman AH, Gallagher CJ. Immunogenicity of botulinum toxins. J Neural Transm. 2013;120(2):275-290.
106. FDA Approval Package for Xeomin ${ }^{\circledR}$ (2010) (incobotulinumtoxinA) Injection. vol Application Number 125360 [webpage on the Internet]. Silver Spring, MD: US Food and Drug Administration; 2010. Available from: http://www.accessdata.fda.gov/drugsatfda_docs/ nda/2010/125360s0000TOC.cfm. Accessed June 5, 2014.

107. Gelb DJ, Yoshimura DM, Olney RK, Lowenstein DH, Aminoff MJ. Change in pattern of muscle activity following botulinum toxin injections for torticollis. Ann Neurol. 1991;29(4):370-376.

108. Brashear A, Bergan K, Wojcieszek J, Siemers ER, Ambrosius W. Patients' perception of stopping or continuing treatment of cervical dystonia with botulinum toxin type A. Mov Disord. 2000;15(1): 150-153.

109. Naumann M, Carruthers A, Carruthers J, et al. Meta-analysis of neutralizing antibody conversion with onabotulinumtoxinA (BOTOX(R)) across multiple indications. Mov Disord. 2010;25(13): 2211-2218.

110. Mohindru A, Bulloch S, Kronfeld N, James C. Analysis of clinical and non-clinical, peer-reviewed published studies investigating the use of commercially available botulinum toxins: an online and offline literature review. Poster presented at: 2nd International Congress on Treatment of Dystonial; May 9-12 May; 2013; Hannover, Germany.

111. Naumann M, Lowe NJ, Kumar CR, Hamm H; Hyperhidrosis Clinical Investigators Group. Botulinum toxin type a is a safe and effective treatment for axillary hyperhidrosis over 16 months: a prospective study. Arch Dermatol. 2003;139(6):731-736.

112. Ginsberg D, Gousse A, Keppenne V, et al. Phase 3 efficacy and tolerability study of onabotulinumtoxinA for urinary incontinence from neurogenic detrusor overactivity. J Urol. 2012;187(6):2131-2139.

113. Coelho A, Cruz F, Cruz CD, Avelino A. Spread of onabotulinumtoxinA after bladder injection. Experimental study using the distribution of cleaved SNAP-25 as the marker of the toxin action. Eur Urol. 2012;61(6):1178-1184.

114. Coelho A, Cruz F, Cruz CD, Avelino A. Effect of onabotulinumtoxinA on intramural parasympathetic ganglia: an experimental study in the guinea pig bladder. J Urol. 2012;187(3):1121-1126.

115. Durham PL, Cady R, Cady R. Regulation of calcitonin gene-related peptide secretion from trigeminal nerve cells by botulinum toxin type A: implications for migraine therapy. Headache. 2004;44(1):35-42; discussion 42-33.

116. Collins VM, Daly DM, Liaskos M, et al. OnabotulinumtoxinA significantly attenuates bladder afferent nerve firing and inhibits ATP release from the urothelium. BJU Int. 2013;112(7):1018-1026.

117. Aurora SK, Dodick DW, Turkel CC, et al; PREEMPT 1 Chronic Migraine Study Group. OnabotulinumtoxinA for treatment of chronic migraine: results from the double-blind, randomized, placebo-controlled phase of the PREEMPT 1 trial. Cephalalgia. 2010;30(7): 793-803.

118. Dodick DW, Turkel CC, DeGryse RE, et al; PREEMPT Chronic Migraine Study Group. OnabotulinumtoxinA for treatment of chronic migraine: pooled results from the double-blind, randomized, placebo-controlled phases of the PREEMPT clinical program. Headache. 2010;50(6):921-936.

119. Dmochowski R, Chapple C, Nitti VW, et al. Efficacy and safety of onabotulinumtoxinA for idiopathic overactive bladder: a double-blind, placebo controlled, randomized, dose ranging trial. J Urol. 2010;184(6):2416-2422.

120. Information for Healthcare Professionals: OnabotulinumtoxinA (marketed as Botox/Botox Cosmetic), AbobotulinumtoxinA (marketed as Dysport) and RimabotulinumtoxinB (marketed as Myobloc) [webpage on the Internet]. US Food and Drug Administration; 2009. Available from: http://www.fda.gov/Drugs/DrugSafety/PostmarketDrugSafety InformationforPatientsandProviders/DrugSafetyInformationforHeathca reProfessionals/ucm174949.htm. Accessed October 10, 2013.

121. Pickett A, Mewies M. Serious issues relating to the clinical use of unlicensed botulinum toxin products. J Am Acad Dermatol. 2009;61(1):149-150.

122. Hunt T, Clarke K. Potency of the botulinum toxin product CNBTX-A significantly exceeds labeled units in standard potency test. $J$ Am Acad Dermatol. 2008;58(3):517-518.

123. Chertow DS, Tan ET, Maslanka SE, et al. Botulism in 4 adults following cosmetic injections with an unlicensed, highly concentrated botulinum preparation. JAMA. 2006;296(20):2476-2479. 


\section{Publish your work in this journal}

Biologics: Targets \& Therapy is an international, peer-reviewed journal focusing on the patho-physiological rationale for and clinical application of Biologic agents in the management of autoimmune diseases, cancers or other pathologies where a molecular target can be identified. This journal is indexed on PubMed Central, CAS, EMBase, Scopus
Dovepress

and the Elsevier Bibliographic databases. The manuscript management system is completely online and includes a very quick and fair peerreview system, which is all easy to use. Visit http://www.dovepress. com/testimonials.php to read real quotes from published authors. 